\title{
Patient-ventilator asynchronies during mechanical ventilation: current knowledge and research priorities
}

Candelaria de Haro ${ }^{1,2^{*}}$ D , Ana Ochagavia ${ }^{1,2}$, Josefina López-Aguilar ${ }^{1,2}$, Sol Fernandez-Gonzalo ${ }^{1,3}$, Guillem Navarra-Ventura', Rudys Magrans ${ }^{1,2}$, Jaume Montanyà', Lluís Blanch ${ }^{1,2}$ and the Asynchronies in the Intensive Care Unit (ASYNICU) Group

From The 3rd International Symposium on Acute Pulmonary Injury Translational Research, under the auspices of the: 'INSPIRES ${ }^{\oplus 1}$

Amsterdam, the Netherlands. 4-5 December 2018

* Correspondence: cdeharo@tauli.
cat
${ }^{1}$ Critical Care Center, Hospital
Universitari Parc Taulí, Institut
d'Investigació i Innovació Parc Taulí
I3PT, Universitat Autònoma de
Barcelona, Parc Taulí 1, 08208
Sabadell, Spain
${ }^{2}$ CIBERES, Instituto de Salud Carlos
III, Madrid, Spain
Full list of author information is
available at the end of the article

* Correspondence: cdeharo@tauli. cat Universitari Parc Taulí, Institut d'Investigació i Innovació Parc Taulí I3PT, Universitat Autònoma de Barcelona, Parc Taulí 1, 08208

Full list of author information is

\begin{abstract}
Background: Mechanical ventilation is common in critically ill patients. This lifesaving treatment can cause complications and is also associated with long-term sequelae. Patient-ventilator asynchronies are frequent but underdiagnosed, and they have been associated with worse outcomes.

Main body: Asynchronies occur when ventilator assistance does not match the patient's demand. Ventilatory overassistance or underassistance translates to different types of asynchronies with different effects on patients. Underassistance can result in an excessive load on respiratory muscles, air hunger, or lung injury due to excessive tidal volumes. Overassistance can result in lower patient inspiratory drive and can lead to reverse triggering, which can also worsen lung injury. Identifying the type of asynchrony and its causes is crucial for effective treatment.

Mechanical ventilation and asynchronies can affect hemodynamics. An increase in intrathoracic pressure during ventilation modifies ventricular preload and afterload of ventricles, thereby affecting cardiac output and hemodynamic status. Ineffective efforts can decrease intrathoracic pressure, but double cycling can increase it. Thus, asynchronies can lower the predictive accuracy of some hemodynamic parameters of fluid responsiveness.

New research is also exploring the psychological effects of asynchronies. Anxiety and depression are common in survivors of critical illness long after discharge. Patients on mechanical ventilation feel anxiety, fear, agony, and insecurity, which can worsen in the presence of asynchronies. Asynchronies have been associated with worse overall prognosis, but the direct causal relation between poor patient-ventilator interaction and worse outcomes has yet to be clearly demonstrated. Critical care patients generate huge volumes of data that are vastly underexploited. New monitoring systems can analyze waveforms together with other inputs, helping us to detect, analyze, and even predict asynchronies. Big data approaches promise to help us understand asynchronies better and improve their diagnosis and management.

(Continued on next page)
\end{abstract}


(Continued from previous page)

Conclusions: Although our understanding of asynchronies has increased in recent years, many questions remain to be answered. Evolving concepts in asynchronies, lung crosstalk with other organs, and the difficulties of data management make more efforts necessary in this field.

Keywords: Patient-ventilator interaction, Asynchronies, Mechanical ventilation, Outcome, Heart lung interaction, Psychological disorders, Cognitive, ICU, Critically ill, Big data

\section{Background}

Invasive mechanical ventilation is the most common means of life support applied in critical care medicine. Although mechanical ventilation often helps save lives, the mortality associated with this technique is very high. In addition, survivors of mechanical ventilation may experience significant long-term morbidity resulting in substantially reduced functional status and ability to complete activities of daily living [1-3]. Optimal patient-ventilator interaction is crucial to assure comfort with mechanical ventilation and to avoid poor outcomes [4]. Patient-ventilator asynchronies (PVA) are the consequence of a mismatch between patients' needs and the assistance delivered by the ventilator. PVA can be classified depending on the phase of the respiratory cycle in which they occur. The most frequent PVA are ineffective efforts, followed by double cycling. Its causes, consequences, and management vary depending on the type (Figs. 1 and 2) [5, 6]. This review article aims to summarize what is known about patient-ventilator interaction and asynchronies in mechanical ventilation, to show its effects on outcomes, and to describe new directions in research about these questions.

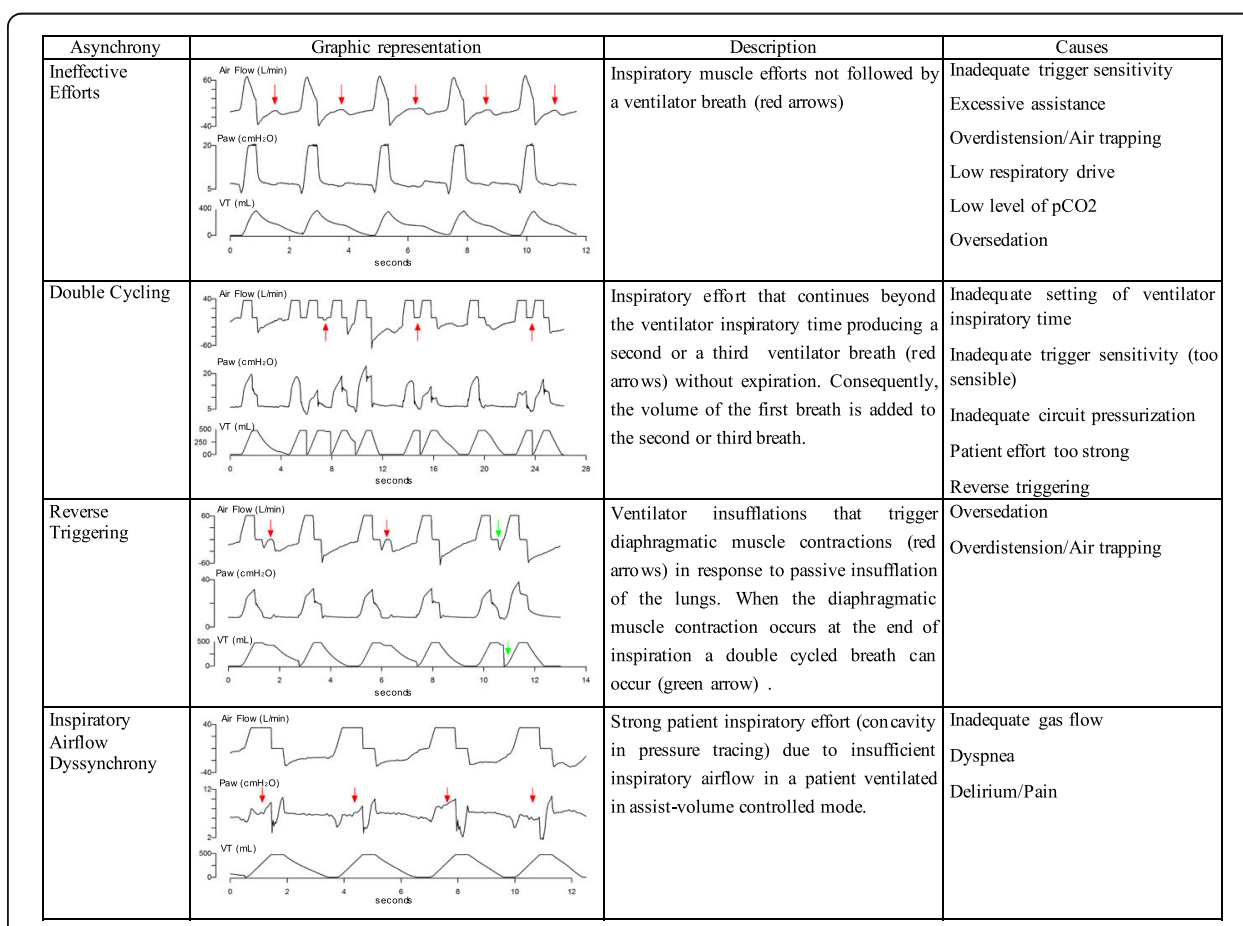

Fig. 1 Representation and description of the most common asynchronies. Ineffective efforts, double cycling, reverse triggering, and inspiratory airflow dyssynchrony are graphically represented and described together with their causes. Red arrows indicate where the asynchrony described is present 
(a)

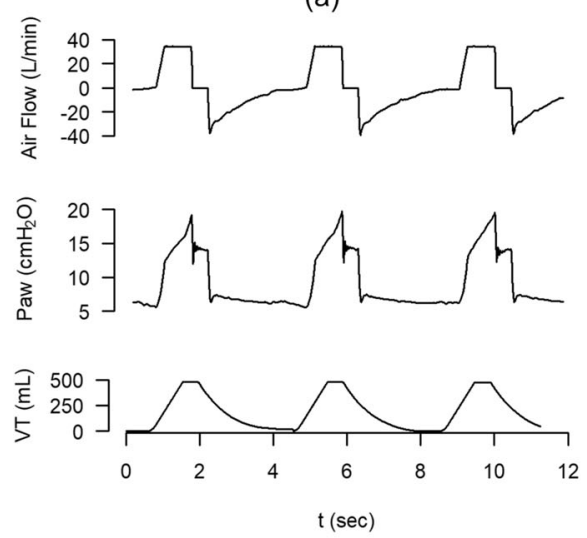

(c)
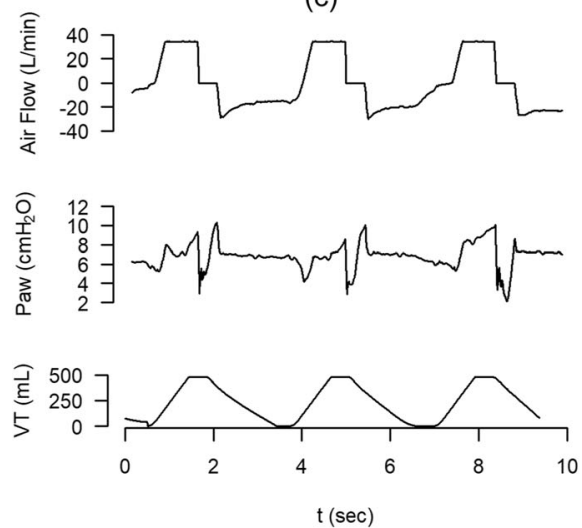

(b)

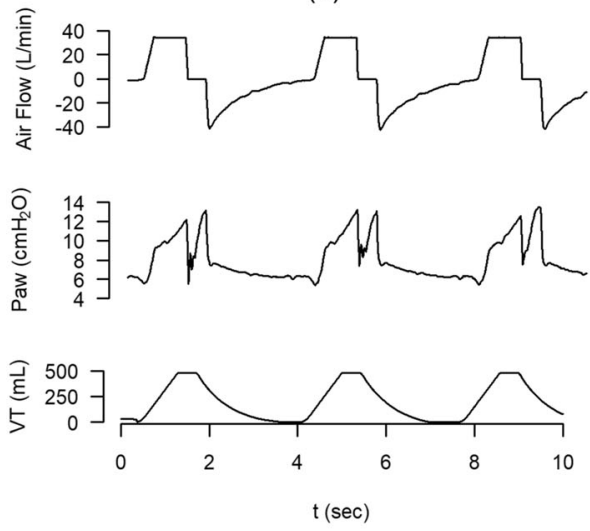

(d)
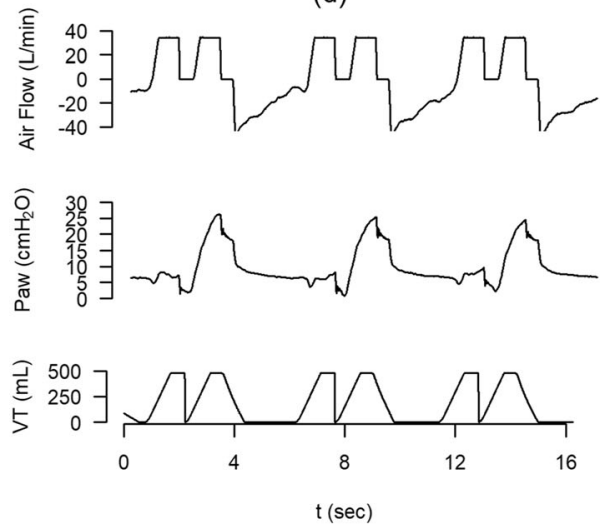

Fig. 2 Inspiratory airflow dyssynchrony. Sequence of airflow and airway pressure waveforms corresponding to a same patient in the same day ventilated in assist volume control mode. Set airflow is insufficient for the patient's needs and originated different degrees of airflow dyssynchrony or starvation. a Mild airflow dyssynchrony. $\mathbf{b}, \mathbf{c}$ The progression of airflow dyssynchrony through a more severe stage. $\mathbf{d}$ The appearance of double cycling secondary to a huge and large inspiratory effort

\section{Main text}

\section{Evolving concepts on patient-ventilator interaction and asynchronies}

Patient-ventilator interaction has been investigated for years [5, 7, 8]. Authors have examined various factors related to ventilator mode, ventilator settings, and patient characteristics that can affect patient-ventilator interaction [4, 5, 9], and have identified many types of asynchronies. Some factors associated with different types of asynchronies have been analyzed, and different mechanisms to reduce their incidence have been studied [10]. Nevertheless, detecting PVA remains a challenge, requiring the application of advanced knowledge about respiratory physiology to interpret ventilator waveforms by analyzing their shape during different periods of the breath cycle (inspiration, transition from inspiration to expiration, and expiration) [5, 6, 8, 11, 12]. Until recently, such analyses required the physical presence of an expert physician at the bedside and were thus only possible during brief, intermittent periods.

PVA occurs when there is a mismatch between the ventilator and the patient in terms of demand or breath delivery timing. Recently, Pham et al. [6] proposed a classification of PVA based on the appropriateness of the level of assistance provided by the 
ventilator. Assistance is deemed insufficient when the ventilator fails to meet the patient's flow demand. Inspiratory airflow dyssynchrony due to insufficient ventilator airflow (also named flow starvation) results in the patient's inspiratory effort continuing beyond the ventilator's inspiratory time. When the patient's effort is strong enough, a second breath can be triggered with no or minimal expiration (called double cycling or breath stacking), resulting in a potentially dangerous increase in tidal volume. Inspiratory airflow dyssynchrony develops mainly when ventilators are set to deliver fixed flow and/or lower tidal volumes in patients with high inspiratory flow demands that vary from breath to breath $[13,14]$. Potential consequences of low assistance are excessive load on the respiratory muscles, air hunger promoting limbic, paralimbic, and cerebellar activation in the brain [15], and ventilator-induced lung injury due to excessive tidal volume. Moreover, strong inspiratory efforts can increase transvascular pressure gradients and tidal recruitment associated with pendelluft flow and regional lung overdistension [16, 17]. Vigorous spontaneous efforts impact non-dependent and dependent lung regions differently, increasing inspiratory distension but also apparently worsening injury in the dependent lung because diaphragm contraction is poorly transmitted to the remainder of the pleural surface and is thus "confined" to the dependent lung [18]. It can be difficult to detect asynchronies due to insufficient assistance.

By contrast, assistance is deemed excessive when the ventilator provides flow in excess of the patient's demand. Patients with low inspiratory drive due to sedation or excessive ventilator assistance can develop ineffective efforts occurring during either inspiration or expiration, delayed or prolonged cycling, and reverse triggering [6]. The concept of reverse triggering is evolving. Reverse triggering is a frequently under-recognized form of PVA in which the patient's respiratory center is activated in response to a passive insufflation of the lungs. This PVA originates in respiratory muscle contractions triggered by the ventilator [19]. The physiologic mechanism responsible for reverse triggering seems to be related with mechanoreceptors in the muscles and/or chest wall or in complex spinal reflexes [6]. Passive insufflation of the lungs activates the patient's neurological respiratory center [20]. Recent research has found that reverse triggering could occur not only in patients with acute respiratory distress syndrome or diagnosed of brain death but in all patients receiving mechanical ventilation. Since reverse triggering might be more frequent than expected and could be associated with lung or diaphragm injury, the incidence and causes of reverse triggering warrant urgent investigation [6,21,22]. Esophageal pressure monitoring can help to identify this PVA in deeply sedated patients: a drop in esophageal pressure can be related to diaphragmatic contractions triggered by ventilator insufflations [19]. Reverse triggering can result in stretching in the dependent lung. Proportional to negative intrathoracic pressure, stretching due to reverse triggering can be equivalent to that caused by applying $15 \mathrm{ml} / \mathrm{kg}$ tidal volume. Yoshida et al. [18] recently demonstrated how reverse triggering can worsen pre-existing lung injury through a pendelluft effect from non-dependent lung areas toward dependent areas due to poor transmission of the diaphragm contraction across the pleural surface in an injured lung. Moreover, reverse triggering can result in increased strain and stretch due to breath stacking during double cycling caused by insufficient assistance [19, 23].

In a recent publication, we used the term double cycling to refer to both reverse-triggered or patient-triggered mechanical breaths occurring at any point in 
mechanical ventilation [21]. Other authors [24] use double cycling only when the first breath in a reverse-triggering event is a ventilator-programmed breath not triggered by the patient. Only the breaths originated by a patient's high inspiratory drive were considered as double triggering. Moreover, reverse triggering that does not cause double cycling can be considered an ineffective effort during the different phases of inspiration. Several authors have speculated that reverse triggering without double cycling can cause lengthening contractions of the diaphragm and with double cycling breath-stacking with increased tidal volume in assist pressure control mode, and both tidal volume and airway pressure in assist volume control mode. Recent investigations suggest that reverse triggering is common in critical patients. Interestingly, de Haro et al. [21] found that one third of double-cycling breaths were reverse-triggered. Clinicians must differentiate between double cycling due to insufficient assistance and double cycling due to reverse triggering because these phenomena call for different treatments. Double cycling due to insufficient assistance is associated with rapid respiratory rates, low ventilator airflow, and short ventilator inspiratory time [21, 25]; by contrast, double cycling due to reverse triggering is associated with deep sedation in patients not triggering the ventilator. However, the mechanisms involved in reverse triggering are poorly understood, so the best treatment approach remains to be determined [6]. At present, detecting these types of PVA requires trained observers analyzing waveforms on ventilator screens at the bedside.

\section{Heart-lung interaction in patients with asynchronies}

The heart and lungs are anatomically and functionally linked. The interactions between cardiovascular and respiratory physiology are very complex and include effects related to changes in intrathoracic pressure and lung volumes [26, 27]. Moreover, the hemodynamic effects of ventilation and asynchronies depend on the hemodynamics' stability and the previous status of the cardiopulmonary system.

In mechanically ventilated patients, the inspiratory increase in intrathoracic pressure reduces venous return by increasing right atrial pressure and reduces left ventricular afterload by decreasing transmural left ventricular systolic pressure. Conversely, it can also increase the afterload of the right ventricle considerably. Increased right ventricular afterload results from progressive increases in transpulmonary pressure (difference between alveolar pressure and pleural pressure) associated with increasing lung volume; this effect can be especially important in patients with acute respiratory distress syndrome. Moreover, left ventricular preload can be affected by changes in right ventricular preload and by ventricular interdependence [26-28]. Interestingly, heart-lung interactions may be useful to assess fluid responsiveness in critical care [28, 29].

urthermore, changes in heart load conditions can in turn lead to lung injury. In a recent experimental study, Katira et al. [30] showed that abrupt deflation after sustained inflation can cause acute lung injury; in critical patients, deflation could occur when positive end-expiratory pressure is removed or the patient is disconnected from the ventilator. Apparently, lung injury results from acute left ventricular decompensation (increased left ventricular preload and afterload), which raises the pressure in the pulmonary microvasculature, injuring the endothelium and causing edema, which is in turn potentiated by the surge in pulmonary perfusion. Whether this phenomenon 
observed in experimental animals could occur in patients under mechanical ventilation warrants further investigation.

Unfortunately, the hemodynamic effects caused by different PVA have not been extensively studied. In theory, ineffective efforts decrease intrathoracic pressure and could consequently increase venous return and right ventricular filling. However, there are no physiological data to confirm this hypothesis. On the other hand, our group recently showed that the tidal volume accumulated during double cycling is very high, sometimes even doubling that of normal breaths in volume-targeted modes [21]. In addition, the peak pressure of the second breath is generally greater than that of the first. Both increased volume and pressure could significantly affect preload and afterload, but the hemodynamic consequences of these effects have not been evaluated.

Although dynamic parameters based on heart-lung interactions such as pulse pressure variation (PPV) and stroke volume variation (SVV) accurately predict fluid responsiveness in patients passively adapted to the ventilator, these parameters are not good predictors of fluid responsiveness in patients with spontaneous respiratory activity probably due to multiple causes such as increased preload induced by negative intrathoracic pressure during patient inspiration and the variability of the breathing pattern [31]. In the presence of asynchronies, this effect could be magnified.

In a recent study examining whether PVA affected PPV's ability to predict fluid responsiveness in patients receiving pressure support ventilation, Messina et al. [32] compared 27 patients without PVA versus 27 with PVA as determined by visual inspection of ventilator waveforms. The area under the receiver operating characteristic curve was 0.86 (CI 0.68-0.96) in patients without PVA but only 0.53 (CI 0.33-0.73) in those with PVA $(p=0.018) ;$ PPV $\geq 13 \%$ predicted fluid responsiveness with $78 \%$ sensitivity and $89 \%$ specificity in patients without PVA but only $36 \%$ sensitivity and $46 \%$ specificity in those with asynchronies. PVA significantly affected PPV prediction of fluid responsiveness (OR 8.8 [2.0-38.0]; $p=0.003$ ). They hypothesize that PVA affect the cyclical changes in intrathoracic pressure, resulting in unpredictable and persistent variations of right ventricular preload and left ventricular stroke volume, thereby altering the reliability of PPV in assessing fluid responsiveness. Nevertheless, more physiological and clinical data are needed to determine the implications of these findings in clinical practice.

\section{Can asynchronies impact major outcomes?}

PVA are frequent but underdiagnosed, and they have been associated with worse prognosis: discomfort; sleep disorders [33], which increase the need for sedatives [34]; prolongation of mechanical ventilation [7,35]; increased intensive care unit (ICU) and hospital stays [33]; and increased mortality [4]. Thus, it seems crucial to take action to reduce their incidence [5]. Nevertheless, a direct causal relation between poor patient-ventilator interaction and worse outcomes has yet to be clearly demonstrated, and there is no direct evidence to demonstrate that reducing PVA guarantees better outcomes.

To clarify whether PVA are a direct causative factor of worse outcomes, it is necessary to identify and quantify the occurrence of PVA throughout the entire period of mechanical ventilation. To this end, monitoring systems have recently been developed 
to enable such analyses, and these systems are helping elucidate the potential harmful physiological effects of different types of PVA [36, 37].

Monitoring systems have made possible to analyze the magnitude of PVA and how they are distributed over time, which are crucial factors in the evaluation of the impact of PVA on clinical outcomes. In a secondary analysis, Blanch et al. [4] found that although patients with an asynchrony index $>10 \%$ had similar rates of reintubation and tracheostomy compared to those with lower rates, an asynchrony index $>10 \%$ was associated with higher ICU and hospital mortality and with a trend toward longer duration of mechanical ventilation. Beyond the frequency of PVA, Vaporidi et al. [38] focused on the presence of clusters of ineffective efforts as well as their power and duration, finding that all these aspects were associated with prolonged mechanical ventilation and higher hospital mortality and highlighting the need to examine different dimensions of patient-ventilator interaction. Finally, Rue et al. [39] used Bayesian joint modeling of bivariate and competing risks data to investigate the added value of adding information about the rate of PVA to Sequential Organ Failure Assessment (SOFA) scores to predict outcomes. They found an association between the asynchrony index and live discharge, but including this information did not improve the accuracy of the prognosis of the SOFA score alone. They concluded that a more detailed analysis of PVA, together with other multidimensional data, would be necessary to confirm a causal role on ventilated patients' outcomes and comorbidities. It also remains to be demonstrated whether strategies to optimize patient-ventilator interactions improve outcomes.

De Haro et al. [21] analyzed the incidence, mechanisms, and physiologic implications of double cycling in 67 adults continuously monitored while undergoing various modes of volume- and/or pressure-targeted mechanical ventilation for more than $24 \mathrm{~h}$. They found that, as previously observed by others, the volume of stacked breaths resulting from inspiratory airflow dyssynchrony can double the set tidal volume in volume-controlled ventilation [21]. This higher-than-expected tidal volume exceeds the optimal value set for protective ventilation and could harm lung tissue and respiratory muscles [21, 25], thus contributing to ventilation-associated lung injury [21, 24, 25, 40, 41].

Regarding neuropsychological outcomes, new research is exploring how mechanical ventilation is linked to psychological disorders observed in critically ill patients [42, 43]. Anxiety is one of the most common psychological symptoms reported by critically ill patients [44], affecting between 30 and $80 \%$ of all patients [45]. Patients on mechanical ventilation report worries about breathlessness, choking, or being left alone [46], and up to $47 \%$ of ICU survivors report having felt anxiety and/or fear during mechanical ventilation [47]. It seems that, even after tracheotomy, levels of anxiety do not decrease [44]. However, the direct link between anxiety and asynchronies in mechanically ventilated patients has not been explored yet. Nevertheless, respiratory difficulties, including synchronizing with the respirator, cough, and dyspnea [45, 46], are considered potent drivers of anxiety, agony, and insecurity. Anxiety has been independently associated with dyspnea in critically ill patients undergoing mechanical ventilation, and when ventilator settings are adjusted, dyspnea is reduced in at least a third of patients [48]. Therefore, asynchronies and anxiety in ICU patients could be, somehow, potentially related. 
Anxiety is a state of psychological distress and physiological discomfort that, if prolonged, delays healing and predisposes to difficulties in weaning from mechanical ventilation [44]. Jubran et al. [49] also found that mechanically ventilated patients with depressive symptoms were three times more likely to experience weaning failure and death. Furthermore, high levels of anxiety often prompt professionals to apply higher sedation doses or restraints, leading to immobility, decreased level of consciousness, and loss of protective reflexes [46].

Despite the importance of the early detection of adverse psychological outcomes during ICU stay, neither anxiety nor depressive symptoms are routinely assessed in mechanically ventilated critically ill patients. In fact, most of the little information available about psychological disorders derives from the studies in ICU survivors [46]. After ICU discharge, 23 to $50 \%$ of survivors have generalized, nonspecific anxiety [2, 50, 51], and although it improves over time, anxiety levels in ICU survivors are higher than those observed in medical inpatients (5 to 20\%) [2]. Nevertheless, 15 to $43 \%$ of survivors continue to have symptoms of anxiety 6 months [51] and 1 year [52] after discharge, and $60 \%$ also have other mental health problems such as post-traumatic stress disorder (PTSD) [53-55] and depression [50, 56]. These long-term mental health problems in ICU survivors are often associated with worse quality of life [2, 3].

\section{Big data techniques applied to large observational databases to improve the management of ventilated patients}

In medical research, pragmatic research attempts to approach problems from a broad and, in a sense, a realistic perspective. For example, observational studies of medical interventions may more closely reflect daily clinical practice [57]. However, the main drawback of observational studies is the potential bias and confounding factors, being difficult to establish an independent association between methods/strategies/treatments and outcome variables. The access to large databases of heterogeneous populations with high levels of complexity is key for observational studies to the extent researchers are aware of confounding and able to measure them.

Mechanically ventilated critically ill patients continuously generate huge volumes of data of varying complexity and temporal resolution [36, 58]. Some data (e.g., physiologic waveforms) are generated at very high temporal resolutions, while others are generated at much lower temporal resolutions. Whereas data about laboratory test results might be generated on a daily basis, two medical devices (e.g., multiparameter monitor and ventilator) connected to a mechanically ventilated patient record about 10 different waveforms (electrocardiographic, plethysmographic, capnographic, respiratory, arterial blood pressure, airway pressure, gas flow, volume) at 200 points per second or more, thus producing a total of 172.8 million data points each day or 1.04 billion over the average duration of mechanical ventilation. Traditionally, most of these data are underexploited, becoming unavailable immediately or within 24 to $48 \mathrm{~h}[58,59]$. Thus, the potential to discover new patterns and extract valuable information to support diagnosis or to predict the time course of a patient's condition is lost.

During mechanical ventilation, patient-ventilator interaction alternates between periods of complete synchrony and periods with clusters of frequent asynchronies [38]. Yet, physicians optimize mechanical ventilation by assessing waveforms on bedside 
monitors based on their understanding of the physiological principles involved and evidence from previous studies; however, today's guidelines for ICUs derive from a scant evidence base, considering the potential evidence base given the massive data generated in the ICU [59]. It should come as no surprise that most physicians perform poorly at managing patient-ventilator interactions and do not recognize common forms of patient-ventilator asynchronies [11], but an equally important problem is that even the most highly skilled professionals can observe only a small proportion of these waveforms, thus increasing the probability of misinterpretation due to sampling errors.

For this reason, there is an urgent need for technological and analytic tools to deal with these pragmatic observational data. Big data promises to help refine our approach to PVA, improving our understanding of the various phenomena, their detection, and their treatment. At present, the continuous and automatic detection of asynchronies is an emerging technological area. Table 1 shows a comparison of some automated methods for patient-ventilator asynchrony detection [60]. However, it can be challenging to implement big data solutions in ICUs. These solutions involve new ethical issues; require investments in technical deployment to resolve problems related to interoperability, network connections, digital storage, etc.; depend on active

Table 1 Comparison of some automated methods for patient-ventilator asynchrony detection

\begin{tabular}{|c|c|c|c|}
\hline & Type of PVA & Algorithm & Performance \\
\hline $\begin{array}{l}\text { Gholami } \\
\text { et al. (2018) } \\
\text { [69] }\end{array}$ & $\begin{array}{l}\text { Cycling asynchrony (premature } \\
\text { and delayed cycling) }\end{array}$ & $\begin{array}{l}\text { ML: Random forest and } k \text {-fold cross } \\
\text { validation } \\
\text { Pressure and airflow signals } \\
N=11 \text { patients ( } 1377 \text { breaths) }\end{array}$ & $\begin{array}{l}\text { Se } 89-97 \%, \text { Sp } 93- \\
\text { 99\%, Kappa index } 0.9\end{array}$ \\
\hline $\begin{array}{l}\text { ventMAP } \\
\text { platform } \\
\text { Adams } \\
\text { et al. } \\
\text { (2017) [70] }\end{array}$ & $\begin{array}{l}\text { Double-trigger and breath } \\
\text { stacking }\end{array}$ & $\begin{array}{l}\text { Rule-based algorithm } \\
\text { Pressure and airflow signals } \\
\text { Derivation cohort, } N=16 \text { patients } \\
\text { ( } 5075 \text { breaths); validation cohort, } \\
N=17 \text { patients ( } 4644 \text { breaths) }\end{array}$ & $\begin{array}{l}\text { Se } 94-96.7 \%, \text { Sp } 92- \\
98 \% \text {, Acc } 92.2-97.7 \% \\
\text { (on the validation } \\
\text { cohort) }\end{array}$ \\
\hline $\begin{array}{l}\text { Neurosync } \\
\text { index } \\
\text { Sinderby et } \\
\text { al. (2013) } \\
\text { [71] }\end{array}$ & $\begin{array}{l}\text { Patient-ventilator interaction } \\
\text { classification (asynchronous, } \\
\text { dyssynchronous or synchronous) }\end{array}$ & $\begin{array}{l}\text { Rule-based timings algorithm } \\
\text { EAdi and pressure signals } \\
N=24 \text { patients }\end{array}$ & $\begin{array}{l}\text { ICC } 0.95 \text { vs. Colombo } \\
\text { et al. }(2011) \text { [5] }\end{array}$ \\
\hline $\begin{array}{l}\text { Better } \\
\text { Care }^{\circledR} \\
\text { system } \\
\text { Blanch et } \\
\text { al. (2012) } \\
{[37]}\end{array}$ & $\begin{array}{l}\text { Ineffective efforts during } \\
\text { expiration }\end{array}$ & $\begin{array}{l}\text { Rule-based combining digital signal } \\
\text { processing techniques and ROC } \\
\text { curves } \\
\text { Airflow signal } \\
\text { Cohort } 1: N=8 \text { patients ( } 1024 \\
\text { breaths) } \\
\text { Cohort } 2: N=8 \text { patients ( } 9600 \\
\text { breaths) with EAdi signal as } \\
\text { reference }\end{array}$ & $\begin{array}{l}\text { Se } 91.5 \%, \text { Sp } 91.7 \%, \\
\text { PPV } 80.3 \%, \text { NPV 96.7\%, } \\
\text { Kappa index } 0.797 \\
\text { (vs. the expert's } \\
\text { Classification) } \\
\text { Se } 65.2 \%, \text { Sp } 99.3 \%, \\
\text { PPV } 90.8 \%, \text { NPV 96.5\%, } \\
\text { Kappa index } 0.739 \\
\text { (vs. EAdi signal) }\end{array}$ \\
\hline $\begin{array}{l}\text { Gutierrez et } \\
\text { al. (2011) } \\
\text { [72] }\end{array}$ & $\begin{array}{l}\text { Index for asynchronous/no } \\
\text { asynchronous breaths }\end{array}$ & $\begin{array}{l}\text { Time-frequency analysis } \\
\text { Airflow signals } \\
N=110 \text { patients }\end{array}$ & $\begin{array}{l}\text { Se } 83 \% \text {, Sp } 83 \% \text { when } \\
\text { index }<43 \% \text { for } \mathrm{Al}> \\
10 \%\end{array}$ \\
\hline $\begin{array}{l}\text { Mulqueeny } \\
\text { et al. (2007) } \\
\text { [73] }\end{array}$ & $\begin{array}{l}\text { Ineffective triggering and double } \\
\text { triggering }\end{array}$ & $\begin{array}{l}\text { Rule-based and digital signal } \\
\text { processing methods } \\
\text { Airflow and pressure signals } \\
N=20 \text { patients ( } 3343 \text { breaths) }\end{array}$ & Se $91 \%$, Sp $97 \%$ \\
\hline $\begin{array}{l}\text { PVI monitor } \\
\text { Younes et } \\
\text { al. (2007) } \\
{[74]}\end{array}$ & Ineffective efforts & $\begin{array}{l}\text { Rule-based } \\
\text { Equation of motion from pressure, } \\
\text { airflow, and Peso signals } \\
N=21 \text { patients }\end{array}$ & Se $79.7 \%$ \\
\hline
\end{tabular}

Abbreviations: $M L$ machine learning, Se sensitivity, Sp specificity, ICC intraclass correlation coefficient, Acc overall accuracy, Peso esophageal pressure, $P P V$ positive predictive value, NPV negative predictive value, $R O C$ receiver operating characteristics, $A l$ asynchrony index according to the definition from Thille et al. [7] 
collaboration among experts from a wide range of areas (physicians, biologists, statisticians, and engineers); and must meet quality standards [61]. Big data solutions to support daily clinical decision making and improve patient care are based on storing and exploring extremely large observational datasets [58, 61-63].

Fortunately, some steps are being taken in this direction. The Multiparameter and Intelligent Monitoring in Intensive Care (MIMIC) database contains thousands of ICU records reflecting daily clinical routines from a wide variety of sources, making it extremely useful for assessing clinical decision, monitoring algorithms, and testing new research hypothesis [64]. Another interesting initiative is the AEGLE project [65, 66], aimed at identifying ineffective efforts with big data analytics. AEGLE also addresses lung overstretching during assisted ventilation, identifying injurious high levels of pressure, and predicting the risk of this phenomenon developing within the next few minutes. A recent proof-of-concept study showed that it is feasible to use Hidden Markov Models to predict PVA in critically ill patients and to infer the probability that the number of asynchrony events will be above a given threshold [67]. All these approaches have potential health and economic benefits. Given the growing interest in devising better evidence-based care in the ICU, physicians should become familiar with the opportunities and challenges of big data [68] (Fig. 3).

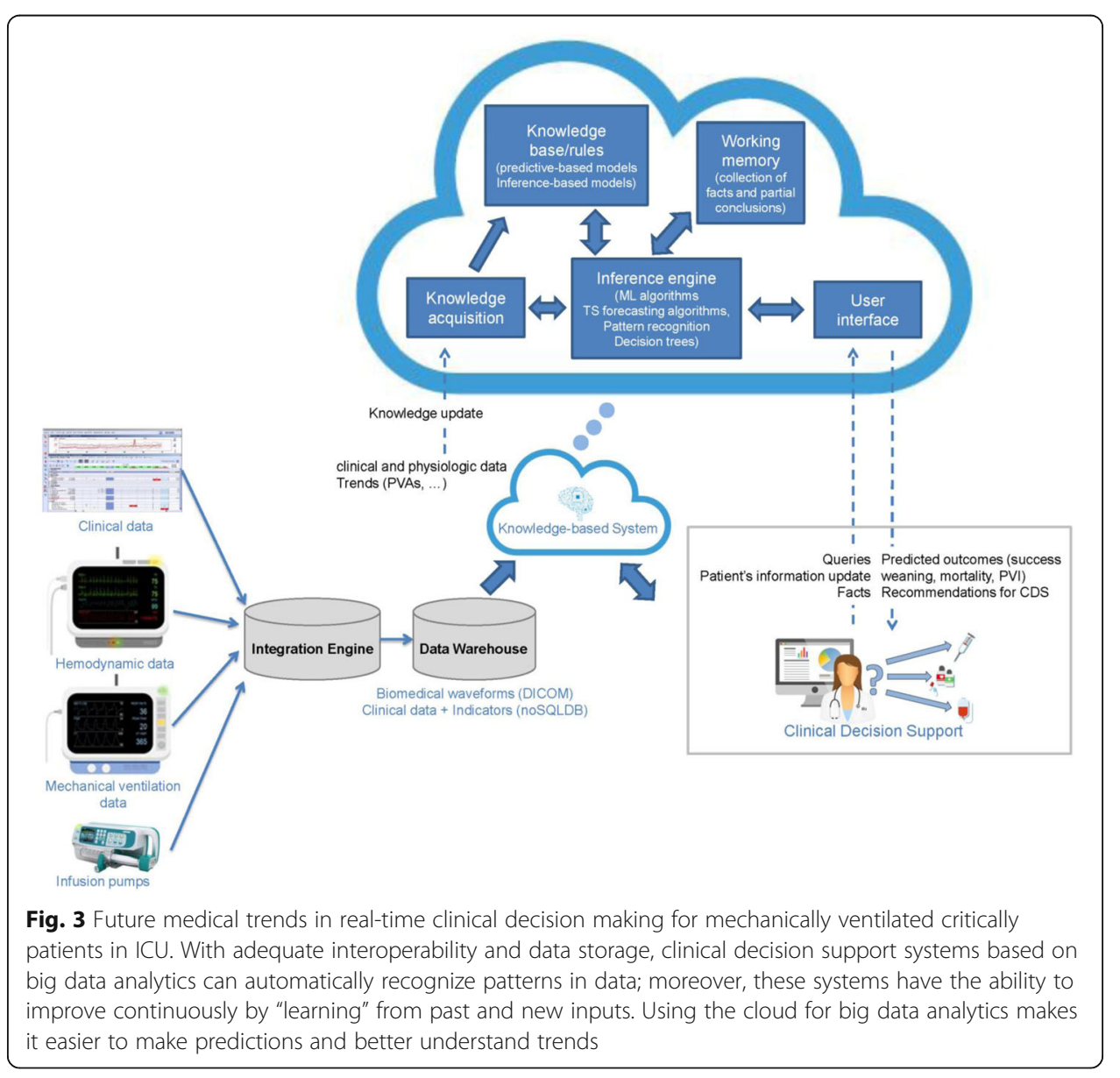




\section{Conclusion}

The results of observational studies evidence that poor patient-ventilator interaction might cause lung and vascular injury and thereby increase mortality. The effects of asynchronies on clinical outcomes remain to be clarified, but the type and presentation of asynchronies over time seems important. Together with damage resulting from the patient's original disease, the short- and long-term consequences of poor patient-ventilator interaction can have devastating effects that hinder discharged patients' complete return to normal activities. Therefore, critical care professionals must strive to improve patient-ventilator interaction. Observational studies could have some limitations on establishing association between patient-ventilator asynchronies and outcomes, and future multicenter studies with bigger population are needed. Finally, software solutions that can identify and analyze asynchronies online and offline may lead to better care and improve outcomes.

\section{Abbreviations}

Acc: Overall accuracy; Al: Asynchrony index; Cl: Confidence interval; EAdi: Electric activity diaphragm; ICC: Intraclass correlation coefficient; ICU: Intensive care unit; ML: Machine learning; NPV: Negative predictive value; OR: Odds ratio; PAW: Pressure airway; PPV: Positive predictive value; PuPV: Pulse pressure variation; PTSD: Post-traumatic stress disorder; PVA: Patient-ventilator asynchronies; ROC: Receiver operating characteristics; Se: Sensibility; SOFA: Sequential Organ Failure Assessment; Sp: Specificity; SW: Stroke volume variation; $V_{\mathrm{t}}$ : Tidal volume

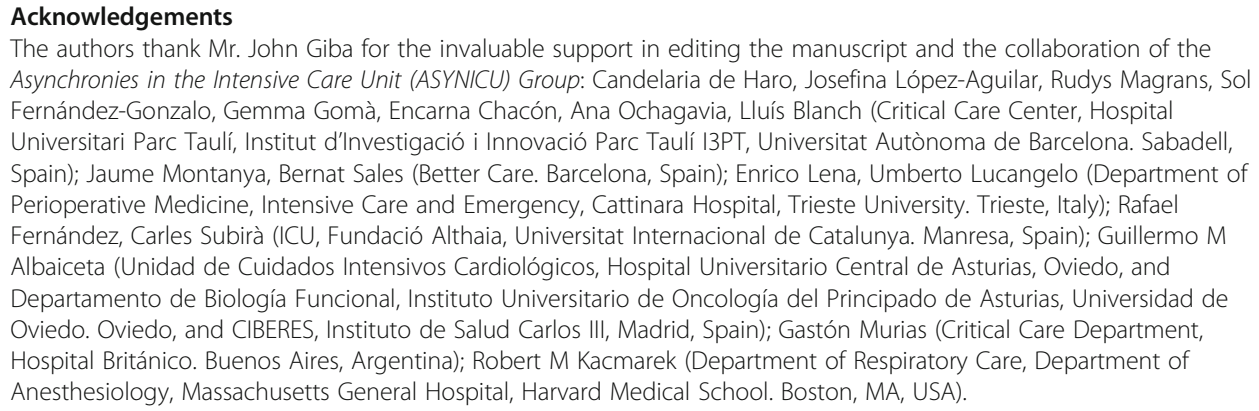

Funding

This work was funded by projects PI13/02204 and PI16/01606, integrated in the Plan Nacional de R+D+I and co-funded by the ISCIII- Subdirección General de Evaluación y el Fondo Europeo de Desarrollo Regional (FEDER). CIBER Enfermedades Respiratorias, and Fundació Parc Taulí.

This article did not receive sponsorship for publication.

Availability of data and materials

Not applicable.

\section{About this supplement}

This article has been published as part of the supplement Intensive Care Medicine Experimental Volume 7 Supplement 1 2019: Proceedings from the Third International Symposium on Acute Pulmonary Injury and Translational Research (INSPIRES III). The full contents of the supplement are available at https://icm-experimental.springeropen.com/articles/ supplements/volume-7-supplement-1.

\section{Authors' contributions}

$\mathrm{CdH}$ and LB have contributed to the section "Evolving concepts on patient-ventilator interaction and asynchronies". AO has contributed to the section "Heart Lung Interaction in patients with asynchronies". JLA, SFG, and GNV have contributed to the section "Can asynchronies impact major outcomes?" RM and JM have contributed to the section "Big data techniques applied to large observational databases to improve the management of ventilated patients". All authors read and approved the final manuscript.

Ethics approval and consent to participate

Not applicable. 


\section{Competing interests}

Mr. Montanya and Dr. Blanch own stock options of Better Care SL, which is a research and development spinoff of Corporació Sanitària Parc Taulí (Spain). Drs. Blanch discloses that he is inventor of one Corporació Sanitaria Parc Taulí owned US patent: "Method and system for managed related patient parameters provided by a monitoring device," U.S. Patent No. 12/538,940. The remaining authors declare that they have no competing interests.

\section{Publisher's Note}

Springer Nature remains neutral with regard to jurisdictional claims in published maps and institutional affiliations.

\section{Author details}

${ }^{1}$ Critical Care Center, Hospital Universitari Parc Taulí, Institut d'Investigació i Innovació Parc Taulí I3PT, Universitat Autònoma de Barcelona, Parc Taulí 1, 08208 Sabadell, Spain. ${ }^{2}$ CIBERES, Instituto de Salud Carlos III, Madrid, Spain. ${ }^{3}$ CIBERSAM, Instituto de Salud Carlos III, Madrid, Spain. ${ }^{4}$ Better Care, Barcelona, Spain.

\section{Received: 6 February 2019 Accepted: 7 March 2019}

Published: 25 July 2019

\section{References}

1. Mehta AB, Syeda SN, Wiener RS, Walkey AJ (2015) Epidemiological trends in invasive mechanical ventilation in the United States: a population-based study. J Crit Care 30:1217-1221

2. Jackson JC, Mitchell N, Hopkins RO (2015) Cognitive functioning, mental health, and quality of life in ICU survivors: an overview. Psychiatr Clin North Am 38:91-104

3. Jackson JC, Pandharipande PP, Girard TD, Brummel NE, Thompson JL, Hughes CG, Pun BT, Vasilevskis EE, Morand A, Shintani AK, Hopkins RO, Bernard GR, Dittus RS, Ely EW (2014) Depression, post-traumatic stress disorder, and functional disability in survivors of critical illness in the BRAIN-ICU study: a longitudinal cohort study. Lancet Respir Med 2:369-379

4. Blanch L, Villagra A, Sales B, Montanya J, Lucangelo U, Lujan M, Garcia-Esquirol O, Chacon E, Estruga A, Oliva JC, Hernandez-Abadia A, Albaiceta GM, Fernandez-Mondejar E, Fernandez R, Lopez-Aguilar J, Villar J, Murias G, Kacmarek RM (2015) Asynchronies during mechanical ventilation are associated with mortality. Intensive Care Med 41:633-641

5. Subira C, de Haro C, Magrans R, Fernandez R, Blanch L (2018) Minimizing asynchronies in mechanical ventilation: current and future trends. Respir Care 63:464-478

6. Pham T, Telias I, Piraino T, Yoshida T, Brochard L (2018) Asynchrony consequences and management. Crit Care Clin 34:325-341

7. Thille AW, Rodriguez P, Cabello B, Lellouche F, Brochard L (2006) Patient-ventilator asynchrony during assisted mechanical ventilation. Intensive Care Med 32:1515-1522

8. Gilstrap D, Maclntyre N (2013) Patient-ventilator interactions. Implications for clinical management. Am J Respir Crit Care Med 188:1058-1068

9. Spieth PM, Guldner A, Huhle R, Beda A, Bluth T, Schreiter D, Ragaller M, Gottschlich B, Kiss T, Jaber S, Pelosi P, Koch T, Gama de Abreu M (2013) Short-term effects of noisy pressure support ventilation in patients with acute hypoxemic respiratory failure. Crit Care 17:R261

10. Kondili E, Prinianakis G, Georgopoulos D (2003) Patient-ventilator interaction. Br J Anaesth 91:106-119

11. Colombo D, Cammarota G, Alemani M, Carenzo L, Barra FL, Vaschetto R, Slutsky AS, Della Corte F, Navalesi P (2011) Efficacy of ventilator waveforms observation in detecting patient-ventilator asynchrony. Crit Care Med 39:2452-2457

12. de Wit M (2011) Monitoring of patient-ventilator interaction at the bedside. Respir Care 56:61-72

13. Figueroa-Casas JB, Montoya R (2016) Effect of tidal volume size and its delivery mode on patient-ventilator dyssynchrony. Ann Am Thorac Soc 13:2207-2214

14. Telias I, Brochard L, Goligher EC (2018) Is my patient's respiratory drive (too) high? Intensive Care Med 44(11):1936-1939

15. Evans KC, Banzett RB, Adams L, McKay L, Frackowiak RS, Corfield DR (2002) BOLD fMRI identifies limbic, paralimbic, and cerebellar activation during air hunger. J Neurophysiol 88:1500-1511

16. Maclntyre NR, McConnell R, Cheng KC, Sane A (1997) Patient-ventilator flow dyssynchrony: flow-limited versus pressurelimited breaths. Crit Care Med 25:1671-1677

17. Kallet RH, Alonso JA, Luce JM, Matthay MA (1999) Exacerbation of acute pulmonary edema during assisted mechanical ventilation using a low-tidal volume, lung-protective ventilator strategy. Chest 116:1826-1832

18. Yoshida T, Amato MBP, Kavanagh BP (2018) Understanding spontaneous vs. ventilator breaths: impact and monitoring. Intensive Care Med 44(12):2235-2238

19. Akoumianaki E, Lyazidi A, Rey N, Matamis D, Perez-Martinez N, Giraud R, Mancebo J, Brochard L, Richard JM (2013) Mechanical ventilation-induced reverse-triggered breaths: a frequently unrecognized form of neuromechanical coupling. Chest 143:927-938

20. Murias G, de Haro C, Blanch L (2016) Does this ventilated patient have asynchronies? Recognizing reverse triggering and entrainment at the bedside. Intensive Care Med 42:1058-1061

21. de Haro C, Lopez-Aguilar J, Magrans R, Montanya J, Fernandez-Gonzalo S, Turon M, Goma G, Chacon E, Albaiceta GM, Fernandez R, Subira C, Lucangelo U, Murias G, Rue M, Kacmarek RM, Blanch L (2018) Double cycling during mechanical ventilation: frequency, mechanisms, and physiologic implications. Crit Care Med 46:1385-1392

22. Delisle S, Charbonney E, Albert M, Ouellet P, Marsolais P, Rigollot M, Savary D, Richard JM, Serri K (2016) Patientventilator asynchrony due to reverse triggering occurring in brain-dead patients: clinical implications and physiological meaning. Am J Respir Crit Care Med 194:1166-1168

23. Yoshida T, Nakamura MAM, Morais CCA, Amato MBP, Kavanagh BP (2018) Reverse triggering causes an injurious inflation pattern during mechanical ventilation. Am J Respir Crit Care Med 198(8):1096-1099

24. Beitler JR, Sands SA, Loring SH, Owens RL, Malhotra A, Spragg RG, Matthay MA, Thompson BT, Talmor D (2016) Quantifying unintended exposure to high tidal volumes from breath stacking dyssynchrony in ARDS: the BREATHE criteria. Intensive Care Med 42:1427-1436 
25. PohIman MC, McCallister KE, Schweickert WD, Pohlman AS, Nigos CP, Krishnan JA, Charbeneau JT, Gehlbach BK, Kress JP, Hall JB (2008) Excessive tidal volume from breath stacking during lung-protective ventilation for acute lung injury. Crit Care Med 36:3019-3023

26. Pinsky MR (2018) Cardiopulmonary interactions: physiologic basis and clinical applications. Ann Am Thorac Soc 15:S45-S48

27. Feihl F, Broccard AF (2009) Interactions between respiration and systemic hemodynamics. Part I: basic concepts. Intensive Care Med 35:45-54

28. Pinsky MR (2012) Heart lung interactions during mechanical ventilation. Curr Opin Crit Care 18:256-260

29. Pinsky MR (2014) Functional haemodynamic monitoring. Curr Opin Crit Care 20:288-293

30. Katira BH, Engelberts D, Otulakowski G, Giesinger RE, Yoshida T, Post M, Kuebler WM, Connelly KA, Kavanagh BP (2018) Abrupt deflation after sustained inflation causes lung injury. Am J Respir Crit Care Med 198(9):1165-1176

31. Monnet X, Marik PE, Teboul JL (2016) Prediction of fluid responsiveness: an update. Ann Intensive Care 6:111

32. Messina A, Colombo D, Cammarota G, De Lucia M, Cecconi M, Antonelli M, Corte FD, Navalesi P (2015) Patientventilator asynchrony affects pulse pressure variation prediction of fluid responsiveness. J Crit Care 30:1067-1071

33. Bosma K, Ferreyra G, Ambrogio C, Pasero D, Mirabella L, Braghiroli A, Appendini L, Mascia L, Ranieri VM (2007) Patientventilator interaction and sleep in mechanically ventilated patients: pressure support versus proportional assist ventilation. Crit Care Med 35:1048-1054

34. de Wit M, Pedram S, Best AM, Epstein SK (2009) Observational study of patient-ventilator asynchrony and relationship to sedation level. J Crit Care 24:74-80

35. de Wit M, Miller KB, Green DA, Ostman HE, Gennings C, Epstein SK (2009) Ineffective triggering predicts increased duration of mechanical ventilation. Crit Care Med 37:2740-2745

36. Bodi M, Blanch L, Maspons R (2017) Clinical information systems: an opportunity to measure value, investigate and innovate from the real world. Med Int 41:316-318

37. Blanch L, Sales B, Montanya J, Lucangelo U, Garcia-Esquirol O, Villagra A, Chacon E, Estruga A, Borelli M, Burgueno MJ, Oliva JC, Fernandez R, Villar J, Kacmarek R, Murias G (2012) Validation of the Better Care(R) system to detect ineffective efforts during expiration in mechanically ventilated patients: a pilot study. Intensive Care Med 38:772-780

38. Vaporidi K, Babalis D, Chytas A, Lilitsis E, Kondili E, Amargianitakis V, Chouvarda I, Maglaveras N, Georgopoulos D (2017) Clusters of ineffective efforts during mechanical ventilation: impact on outcome. Intensive Care Med 43:184-191

39. Rue M, Andrinopoulou ER, Alvares D, Armero C, Forte A, Blanch L (2017) Bayesian joint modeling of bivariate longitudinal and competing risks data: an application to study patient-ventilator asynchronies in critical care patients. Biom J 59:1184-1203

40. Chanques G, Kress JP, Pohlman A, Patel S, Poston J, Jaber S, Hall JB (2013) Impact of ventilator adjustment and sedationanalgesia practices on severe asynchrony in patients ventilated in assist-control mode. Crit Care Med 41:2177-2187

41. Gonzalez-Lopez A, Garcia-Prieto E, Batalla-Solis E, Amado-Rodriguez L, Avello N, Blanch L, Albaiceta GM (2012) Lung strain and biological response in mechanically ventilated patients. Intensive Care Med 38:240-247

42. Blanch L, Quintel M (2017) Lung-brain cross talk in the critically ill. Intensive Care Med 43:557-559

43. Quilez ME, Fuster G, Villar J, Flores C, Marti-Sistac O, Blanch L, Lopez-Aguilar J (2011) Injurious mechanical ventilation affects neuronal activation in ventilated rats. Crit Care 15:R124

44. Breckenridge SJ, Chlan L, Savik K (2014) Impact of tracheostomy placement on anxiety in mechanically ventilated adult ICU patients. Heart Lung 43:392-398

45. Schmidt M, Banzett RB, Raux M, Morelot-Panzini C, Dangers L, Similowski T, Demoule A (2014) Unrecognized suffering in the ICU: addressing dyspnea in mechanically ventilated patients. Intensive Care Med 40:1-10

46. Tate JA, Devito Dabbs A, Hoffman LA, Milbrandt E, Happ MB (2012) Anxiety and agitation in mechanically ventilated patients. Qual Health Res 22:157-173

47. Bergbom-Engberg I, Haljamae H (1989) Assessment of patients' experience of discomforts during respirator therapy. Crit Care Med 17:1068-1072

48. Schmidt M, Demoule A, Polito A, Porchet R, Aboab J, Siami S, Morelot-Panzini C, Similowski T, Sharshar T (2011) Dyspnea in mechanically ventilated critically ill patients. Crit Care Med 39:2059-2065

49. Jubran A, Lawm G, Kelly J, Duffner LA, Gungor G, Collins EG, Lanuza DM, Hoffman LA, Tobin MJ (2010) Depressive disorders during weaning from prolonged mechanical ventilation. Intensive Care Med 36:828-835

50. Davydow DS, Desai SV, Needham DM, Bienvenu OJ (2008) Psychiatric morbidity in survivors of the acute respiratory distress syndrome: a systematic review. Psychosom Med 70:512-519

51. McKinley S, Aitken LM, Alison JA, King M, Leslie G, Burmeister E, Elliott D (2012) Sleep and other factors associated with mental health and psychological distress after intensive care for critical illness. Intensive Care Med 38:627-633

52. Wolters AE, Peelen LM, Welling MC, Kok L, de Lange DW, Cremer OL, van Dijk D, Slooter AJ, Veldhuijzen DS (2016) Long-term mental health problems after delirium in the ICU. Crit Care Med 44:1808-1813

53. Davydow DS, Gifford JM, Desai SV, Needham DM, Bienvenu OJ (2008) Posttraumatic stress disorder in general intensive care unit survivors: a systematic review. Gen Hosp Psychiatry 30:421-434

54. Jackson JC, Hart RP, Gordon SM, Hopkins RO, Girard TD, Ely EW (2007) Post-traumatic stress disorder and post-traumatic stress symptoms following critical illness in medical intensive care unit patients: assessing the magnitude of the problem. Crit Care 11:R27

55. Parker AM, Sricharoenchai T, Raparla S, Schneck KW, Bienvenu OJ, Needham DM (2015) Posttraumatic stress disorder in critical illness survivors: a metaanalysis. Crit Care Med 43:1121-1129

56. Davydow DS, Gifford JM, Desai SV, Bienvenu OJ, Needham DM (2009) Depression in general intensive care unit survivors: a systematic review. Intensive Care Med 35:796-809

57. Vandenbroucke JP (2008) Observational research, randomised trials, and two views of medical science. PLoS Med 5:e67

58. Big, intensive data. http://news.mit.edu/2016/big-intensive-data-thomas-heldt-0331. Accessed 26 Nov 2018

59. Celi LA, Mark RG, Stone DJ, Montgomery RA (2013) "Big data" in the intensive care unit. Closing the data loop. Am J Respir Crit Care Med 187:1157-1160

60. Dres M, Rittayamai N, Brochard L (2016) Monitoring patient-ventilator asynchrony. Curr Opin Crit Care 22:246-253

61. Bauer M (2016) Big data, technology, and the changing future of medicine. Medicographia 38:401-409 
62. Cooke CR, Iwashyna TJ (2013) Using existing data to address important clinical questions in critical care. Crit Care Med 41:886-896

63. Murdoch TB, Detsky AS (2013) The inevitable application of big data to health care. JAMA 309:1351-1352

64. Serpa Neto A, Deliberato RO, Johnson AEW, Bos LD, Amorim P, Pereira SM, Cazati DC, Cordioli RL, Correa TD, Pollard TJ, Schettino GPP, Timenetsky KT, Celi LA, Pelosi P, Gama de Abreu M, Schultz MJ (2018) Mechanical power of ventilation is associated with mortality in critically ill patients: an analysis of patients in two observational cohorts. Intensive Care Med 44:1914-1922

65. Potential benefits of adopting AEGLE analytics to improve patient-ventilator interaction. http.//www.aegle-uhealth.eu/ blog/potential-benefits-of-adopting-aegle-analytics-to-improve-patient-ventilator-interaction. Accessed 26 Nov 2018

66. Looking at the ICU ventilator with AEGLE's eyes - using big data analytics to improve mechanical ventilation in ICU. http://www.aegle-uhealth.eu/blog/icu-with-aegle-eyes. Accessed 26 Nov 2018

67. Marchuk Y, Magrans R, Sales B, Montanya J, López-Aguilar J, de Haro C, Gomà G, Subirà C, Fernández R, Kacmarek RM Blanch L (2018) Predicting patient-ventilator asynchronies with Hidden Markov Models. Sci Rep 8:17614

68. Sanchez-Pinto LN, Luo Y, Churpek MM (2018) Big data and data science in critical care. Chest 154:1239-1248

69. Gholami B, Phan TS, Haddad WM, Cason A, Mullis J, Price L, Bailey JM (2018) Replicating human expertise of mechanical ventilation waveform analysis in detecting patient-ventilator cycling asynchrony using machine learning. Comput Biol Med 97:137-144

70. Adams JY, Lieng MK, Kuhn BT, Rehm GB, Guo EC, Taylor SL, Delplanque JP, Anderson NR (2017) Development and validation of a multi-algorithm analytic platform to detect off-target mechanical ventilation. Sci Rep 7:14980

71. Sinderby C, Liu S, Colombo D, Camarotta G, Slutsky AS, Navalesi P, Beck J (2013) An automated and standardized neural index to quantify patient-ventilator interaction. Crit Care 17:R239

72. Gutierrez G, Ballarino GJ, Turkan H, Abril J, De La Cruz L, Edsall C, George B, Gutierrez S, Jha V, Ahari J (2011) Automatic detection of patient-ventilator asynchrony by spectral analysis of airway flow. Crit Care 15:R167

73. Mulqueeny Q, Ceriana P, Carlucci A, Fanfulla F, Delmastro M, Nava S (2007) Automatic detection of ineffective triggering and double triggering during mechanical ventilation. Intensive Care Med 33:2014-2018

74. Younes M, Brochard L, Grasso S, Kun J, Mancebo J, Ranieri M, Richard JC, Younes H (2007) A method for monitoring and improving patient: ventilator interaction. Intensive Care Med 33:1337-1346

\section{Submit your manuscript to a SpringerOpen ${ }^{\circ}$ journal and benefit from:}

- Convenient online submission

- Rigorous peer review

- Open access: articles freely available online

- High visibility within the field

- Retaining the copyright to your article

Submit your next manuscript at $\boldsymbol{\nabla}$ springeropen.com 